\title{
Multidrug-resistant Neisseria gonorrhoeae infection with ceftriaxone resistance and intermediate resistance to azithromycin, Denmark, 2017
}

David Terkelsen ${ }^{1,2}$, Jacob Tolstrup ${ }^{2,3}$, Camilla Hundahl Johnsen ${ }^{4}$, Ole Lund ${ }^{4}$, Helle Kiellberg Larsen ${ }^{3}$, Peder Worning ${ }^{1}$, Magnus

Unemo $0^{5,7}$, Henrik Westh ${ }^{1,6,7}$

1. Department of Clinical Microbiology, Hvidovre Hospital, Copenhagen, Denmark

2. These authors contributed equally to the work

3. Department of Dermatovenerology, Bispebjerg Hospital, Copenhagen, Denmark

4. Department of Bio and Health Informatics, Technical University of Denmark, Lyngby, Denmark

5. WHO Collaborating Centre for Gonorrhoea and other Sexually Transmitted Infections, Department of Laboratory Medicine, Faculty of Medicine and Health, Örebro University, Örebro, Sweden

6. Institute of Clinical Medicine, Faculty of Health and Medical Sciences, University of Copenhagen, Copenhagen, Denmark

7. These authors share last authorship

Correspondence: Henrik Westh (Henrik.torkil.westh@regionh.dk)

Citation style for this article:

Terkelsen David, Tolstrup Jacob, Johnsen Camilla Hundahl, Lund Ole, Larsen Helle Kiellberg, Worning Peder, Unemo Magnus, Westh Henrik. Multidrug-resistant Neisseria gonorrhoeae infection with ceftriaxone resistance and intermediate resistance to azithromycin, Denmark, 2017. Euro Surveill. $2017 ; 22$ (42):pii=17-00659. https://doi.org/10.2807/1560-7917.ES.2017.22.42.17-00659

We describe a multidrug-resistant Neisseria gonorrhoeae infection with ceftriaxone resistance and azithromycin intermediate resistance in a heterosexual man in Denmark, 2017. Whole genome sequencing of the strain GK124 identified MSLT ST1903, NG-MAST ST1614 and all relevant resistance determinants including similar penA resistance mutations previously described in ceftriaxone-resistant gonococcal strains. Although treatment with ceftriaxone $0.5 \mathrm{~g}$ plus azithromycin $2 \mathrm{~g}$ was successful, increased awareness of spread of gonococcal strains threatening the recommended dual therapy is crucial.

In the last decade, high-level resistance to extendedspectrum cephalosporins (ESCs) has been reported in Neisseria gonorrhoeae worldwide, leading to treatment failures with oral cefixime and the more potent injectable ceftriaxone [1-10]. The emergence of ESC resistance has caused public health concern worldwide $[9,11-13]$ and dual antimicrobial therapy is now recommended as the first-line empirical treatment of uncomplicated gonorrhoea in parts of the world including Europe [8,14]. It is worrying that failure to treat pharyngeal gonorrhoea with dual antimicrobial therapy was recently verified in the United Kingdom [15]. Fortunately, ceftriaxone resistance remains rare in Europe [16].

This report describes one rare case of a multidrug-resistant (MDR) N. gonorrhoeae infection with ceftriaxone resistance and intermediate resistance to azithromycin, detected in Denmark in 2017.

\section{Case description}

A heterosexual man in his 20 s from Denmark presented at a general practitioner clinic in Copenhagen, Denmark in January, 2017 with urethritis symptoms that he had had for two days. He had had three unprotected sexual relations with women (of Danish, Chinese and Australian nationality) during the previous 6 months and he had not travelled abroad during that time. He was empirically treated unsuccessfully with a single oral dose of azithromycin $1 \mathrm{~g}$ because non-gonococcal urethritis was suspected. A nucleic acid amplification test (NAAT) (Aptima Combo 2, Hologic Inc.) of urine sampled at the visit to the general practitioner clinic, was positive for $N$. gonorrhoeae and the patient was referred 6 days later to the sexually transmitted diseases (STD) clinic with urethritis symptoms without purulent discharge. Culture from a urethral swab (eight days after symptom onset) was positive for $N$. gonorrhoeae, while NAAT and culture of pharyngeal and rectal samples were negative. He was successfully treated with single doses of ceftriaxone $0.5 \mathrm{~g}$ intramuscularly and azithromycin $2 \mathrm{~g}$ orally and advised to abstain from sexual contacts until test-of-cure (TOC) as outlined in the Danish treatment recommendation [17]. Two weeks after treatment, the TOC using NAAT of urethral and pharyngeal samples were negative and all symptoms were resolved. The patient had no sexual contacts between onset of symptoms and TOC. The Danish sexual contact was NAAT-negative and the two other women were lost to follow-up. 
Antibiotic resistance pattern, multidrug-resistant Neisseria gonorrhoeae patient isolate GK124, Denmark, 2017, compared with four whole-genome-sequenced ceftriaxone-resistant N. gonorrhoeae strains

\begin{tabular}{|c|c|c|c|c|c|}
\hline $\begin{array}{l}\text { Strain (year, country, } \\
\text { name) }\end{array}$ & 2017, Denmark, GK124 & $\begin{array}{c}\text { 2015, Japan, } \mathrm{FC}_{428} \\
{[7]}\end{array}$ & $\begin{array}{l}\text { 2013, Australia, A8806 } \\
\text { (WHO Z }[2,20])\end{array}$ & $\begin{array}{l}\text { 2010, France, F89 } \\
\text { (WHO Y }[1,20])\end{array}$ & $\begin{array}{c}\text { 2009, Japan, Ho41 } \\
\text { (WHO X }[5,20])\end{array}$ \\
\hline \multicolumn{6}{|c|}{ Minimal inhibitory concentration $\left[\mathrm{mg} / \mathrm{L}^{\mathrm{a}}\right]$} \\
\hline Ceftriaxone & $0.25-0.5$ & 0.5 & 0.5 & $1-2$ & $2-4$ \\
\hline Cefixime & 1 & 1 & ND & 4 & 8 \\
\hline Azithromycin & 0.5 & 0.25 & 0.25 & 1 & 1 \\
\hline Spectinomycin & 8 & 8 & $\leq 64$ & 16 & 16 \\
\hline Ciprofloxacin & 132 & 132 & 132 & 132 & $>32$ \\
\hline Benzylpenicillin & $>256$ & $>32$ & 1 & 1 & 4 \\
\hline \multicolumn{6}{|l|}{ Sequence type } \\
\hline MLST & 1903 & 1903 & 7363 & 1901 & 7363 \\
\hline NG-MAST & 1614 & 3435 & 4015 & 1407 & 4220 \\
\hline \multicolumn{6}{|c|}{ Key ceftriaxone resistance alterations in $\mathrm{PBP} 2$} \\
\hline Encoded by penA & $\begin{array}{l}\text { A311V, T483S }(1312 \mathrm{M}, \\
\mathrm{V}_{316 \mathrm{~T}, \mathrm{G}} \mathrm{G}_{55 \mathrm{~S})^{\mathrm{b}}}\end{array}$ & 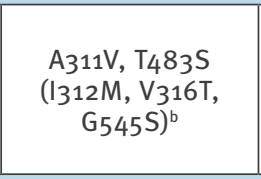 & $\begin{array}{c}\mathrm{A}_{311 \mathrm{~V}} \\
\mathrm{~T}_{483 \mathrm{~S}}\left(\mathrm{I}_{312 \mathrm{M},} \mathrm{V}_{316 \mathrm{~T}}\right. \\
\mathrm{G}_{545 \mathrm{~S})^{\mathrm{b}}}\end{array}$ & $\begin{array}{l}\text { A501P (I312M, } \\
\text { V316T, G545S })^{\mathrm{b}}\end{array}$ & $\begin{array}{c}\text { A311V, } V_{316 P} \\
\text { T483S }(1312 \mathrm{M} \\
\text { G545S }\end{array}$ \\
\hline \multicolumn{6}{|c|}{ Other relevant resistance determinants } \\
\hline PorB1b & $\mathrm{G} 120 \mathrm{~K}, \mathrm{~A}_{121} \mathrm{D}$ & G120K, A121D & G120K, A121D & $\mathrm{G} 120 \mathrm{~K}, \mathrm{~A} 121 \mathrm{~N}$ & G120K, A121D \\
\hline mtr locus & A-del & A-del & ND & A-del & A-del \\
\hline GyrA & S91F, D95A & ND & S91F, D95N & S91F, D95G & S91F, D95N \\
\hline
\end{tabular}

MIC: minimum inhibitory concentration; MLST: multilocus sequence typing; ND: not described; NG-MAST: N. gonorrhoeae multi-antigen sequence typing; PBP2: penicillin-binding protein 2; WHO: World Health Organization reference strain.

a Only whole MIC doubling dilutions are reported.

${ }^{b}$ Mutations in the parenthesis indicate a mosaic penA allele.

\section{Characterisation of the Neisseria gonorrhoeae isolate}

Minimum inhibitory concentration (MIC) values for ceftriaxone, cefixime, azithromycin, spectinomycin, ciprofloxacin, and benzylpenicillin in the $N$. gonorrhoeae strain isolated from the patient, GK124, were determined in duplicate using Etest (bioMerieux, Ballerup, Denmark) and results were interpreted in accordance with the European Committee on Antimicrobial Susceptibility Testing (EUCAST) interpretative criteria [18]. GK124 showed resistance to ceftriaxone (MIC:0.25-0.5 mg/L), cefixime (MIC: $1 \mathrm{mg} / \mathrm{L}$ ), ciprofloxacin (MIC:>32 mg/L) and benzylpenicillin (MIC:>256 mg/L), and intermediate resistance to azithromycin (MIC: $0.5 \mathrm{mg} / \mathrm{L}$ ). GK124 was susceptible to spectinomycin (MIC: $8 \mathrm{mg} / \mathrm{L}$ ) (Table).

Whole genome sequencing (WGS) was performed on an Illumina MiSeq as previously described [19]. The GK124 genome was compared with previously described ceftriaxone-resistant strains (WHO X (Ho41), WHO Y (F89), WHO Z (A8806) $[1,2,5,20]$ and FC428 [7]) using ResFinder 3.0, an update of ResFinder focusing on chromosomal mutational resistance (cge.cbs.dtu. $\mathrm{dk} /$ services/ResFinder/version 3.0) and previous publications (Table). Based on the WGS sequence, the sequence type (ST) of GK124 was ST1903 as derived by multilocus sequence typing (MLST) and ST1614 as derived by $N$. gonorrhoeae multi-antigen sequence typing (NG-MAST) (Table). The draft genome of GK124 can be found under GenBank accession number: PRJEB22246.

Regarding ESC resistance determinants, GK124 con-

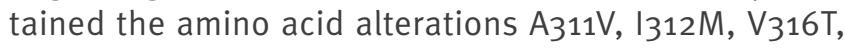
T483S and $\mathrm{G}_{545} \mathrm{~S}$, which indicated that the strain had a mosaic penA allele as well as additional key ceftriaxone resistance mutations $[4,5,7,13,20]$. Furthermore, the strain contained G120K and A121D alterations in PorB $1 \mathrm{~b}$ and the A-deletion in the inverted repeat sequence of the $m t r R$ promoter region that further increase the ESC MICs and contribute to the MDR characteristics of GK124. No mutations associated with azithromycin resistance were found in the $23 \mathrm{~S}$ rRNA gene and, accordingly, the intermediate resistance to azithromycin was due to the $m$ trR resistance determinant and possibly additional unknown mutations. SNPs in gyrA (S91F, D95A), encoding the A subunit of the DNA gyrase, caused the high-level ciprofloxacin resistance [4] (Table). 


\section{Discussion}

This report describes one rare case of MDR N. gonorrhoeae infection with ceftriaxone resistance and intermediate resistance to azithromycin in Denmark, 2017. This case was reported by the national healthcare authorities but has not lead to wider public health actions [21]. Increased awareness of the spread of this type of gonococcal strains that threaten the recommended dual antimicrobial therapy is crucial. This is especially important when the incidence of gonorrhoea is rapidly increasing in many countries, including in Denmark where a sevenfold increase in the gonorrhoea incidence was observed from 2011 to 2016 [21]. This increase in Denmark was not caused by increased awareness as the number of samples tested per year has increased by about $2 \%$ and dual testing for chlamydia and $N$. gonorrhoeae by NAAT is implemented in most of the country. Furthermore, dual antimicrobial therapy with ceftriaxone $500 \mathrm{mg}$ plus azithromycin $2 \mathrm{~g}$ for empiric treatment of gonorrhoea is recommended in Europe [14]; however, the level of implementation of this dual therapy is unknown and several countries still recommend monotherapy with ceftriaxone [22] and even other antimicrobials such as azithromycin.

The MLST ST of GK124, ST1903, has previously been described in the ceftriaxone-resistant strain FC428 isolated in 2015 in Japan [7], but the NG-MAST ST1614 has not been previously associated with ceftriaxone resistance. GK124 contained several key ESC resistance mutations in penA: I312M, $_{3} 16 \mathrm{~T}, \mathrm{G}_{545} \mathrm{~S}$, which are indicator mutations for a mosaic penA allele, and also two $\left(\mathrm{A}_{311 \mathrm{~V}}, \mathrm{~T}_{483} \mathrm{~S}\right)$ of the three key ceftriaxone resistance mutations in the pan-resistant $\mathrm{Ho}_{41}$ (WHO X) $[5,13,20]$. These mutations have also been found in most of the ceftriaxone-resistant strains characterised in detail $[2,5,7,20]$. This provides further evidence that both ceftriaxone-resistant strains and ceftriaxone resistance-determining $\mathrm{PBP}_{2}$ sequences might be spreading internationally [7].

\section{Conclusion}

An MDR N. gonorrhoeae strain with ceftriaxone resistance and intermediate resistance to azithromycin was found in Denmark in 2017. Our patient only had genital infection and was cured by dual antimicrobial therapy. Increased awareness of the spread of this type of gonococcal strains, improved implementation of the recommended dual antimicrobial therapy (for all patients and not only for high-risk populations), partner notification, TOC and appropriate verification/falsification of suspected treatment failures are crucial internationally as the recommended dual antimicrobial therapy is threatened. Ultimately, novel treatment options for gonorrhoea and ideally an effective gonococcal vaccine are imperative.

\section{Acknowledgements}

We thank Lene M. Berthelsen, The Gonococcus Laboratory; Bacteria, Parasites and Fungi; Infectious Disease
Preparedness, Statens Serum Institut for performing the Etest analyses.

\section{Conflict of interest}

None declared.

\section{Authors' contributions}

David Terkelsen, Jacob Tolstrup and Henrik Westh wrote the initial draft. All authors were involved in the analysis of the results and preparations of the final draft of the paper and have accepted the final version. Camilla Hundahl Johnsen and Ole Lund updated the ResFinder software. Camilla Hundahl Johnsen, Ole Lund, Magnus Unemo and Henrik Westh validated the software. Jacob Tolstrup and Helle Kiellberg Larsen treated the patient and his contact and acquired informed consent. Peder Worning and Henrik Westh sequenced the isolate.

\section{References}

1. Unemo M, Golparian D, Nicholas R, Ohnishi M, Gallay A, Sednaoui P. High-level cefixime- and ceftriaxone-resistant Neisseria gonorrhoeae in France: novel penA mosaic allele in a successful international clone causes treatment failure. Antimicrob Agents Chemother. 2012;56(3):1273-80. https:// doi.org/10.1128/AAC.05760-11 PMID: 22155830

2. Lahra MM, Ryder N, Whiley DM. A new multidrug-resistant strain of Neisseria gonorrhoeae in Australia. N Engl J Med. 2014;371(19):1850-1. https://doi.org/10.1056/NEJMc1408109 PMID: 25372111

3. Cámara J, Serra J, Ayats J, Bastida T, Carnicer-Pont D, Andreu A, et al. Molecular characterization of two high-level ceftriaxoneresistant Neisseria gonorrhoeae isolates detected in Catalonia, Spain. J Antimicrob Chemother. 2012;67(8):1858-60. https:// doi.org/10.1093/jac/dks162 PMID: 22566592

4. Unemo M, Shafer WM. Antimicrobial resistance in Neisseria gonorrhoeae in the 21st century: past, evolution, and future. Clin Microbiol Rev. 2014;27(3):587-613. https://doi. org/10.1128/CMR.00010-14 PMID: 24982323

5. Ohnishi M, Golparian D, Shimuta K, Saika T, Hoshina S, Iwasaku K, et al. Is Neisseria gonorrhoeae initiating a future era of untreatable gonorrhea?: detailed characterization of the first strain with high-level resistance to ceftriaxone. Antimicrob Agents Chemother. 2011;55(7):3538-45. https://doi. org/10.1128/AAC.00325-11 PMID: 21576437

6. Gianecini R, Oviedo C, Stafforini G, Galarza P. Neisseria gonorrhoeae resistant to ceftriaxone and cefixime, Argentina. Emerg Infect Dis. 2016;22(6):1139-41. https://doi.org/10.3201/ eid2206.152091 PMID: 27191699

7. Nakayama S, Shimuta K, Furubayashi K, Kawahata T, Unemo M, Ohnishi M. New ceftriaxone- and multidrug-resistant Neisseria gonorrhoeae strain with a novel mosaic penA gene isolated in Japan. Antimicrob Agents Chemother. 2016;60(7):4339-41. https://doi.org/10.1128/AAC.00504-16 PMID: 27067334

8. Unemo M. Current and future antimicrobial treatment of gonorrhoea - the rapidly evolving Neisseria gonorrhoeae continues to challenge. BMC Infect Dis. 2015;15(1):364. https://doi.org/10.1186/s12879-015-1029-2 PMID: 26293005

9. Wi T, Lahra MM, Ndowa F, Bala M, Dillon JR, Ramon-Pardo P, et al. Antimicrobial resistance in Neisseria gonorrhoeae: Global surveillance and a call for international collaborative action. PLoS Med. 2017;14(7):e1002344. https://doi.org/10.1371/ journal.pmed.1002344 PMID: 28686231

10. Golparian D, Ohlsson A, Janson H, Lidbrink P, Richtner T, Ekelund 0 , et al. Four treatment failures of pharyngeal gonorrhoea with ceftriaxone $(500 \mathrm{mg})$ or cefotaxime $(500 \mathrm{mg})$, Sweden, 2013 and 2014. Euro Surveill. 2014;19(30):20862. https://doi.org/10.2807/1560-7917.ES2014.19.30.20862 PMID: 25108533

11. World Health Organization (WHO). Global action plan to control the spread and impact of antimicrobial resistance in Neisseria gonorrhoeae. Geneva: WHO; 2012. Available from: http://www. who.int/reproductivehealth/publications/rtis/9789241503501/ en/

12. European Centre for Disease Prevention and Control (ECDC). Response plan to control and manage the threat of multidrug. resistant gonorrhoea in Europe. Stockholm: ECDC; 2012. 
Available from: https://ecdc.europa.eu/sites/portal/files/ media/en/publications/Publications/1206-ECDC-MDRgonorrhoea-response-plan.pdf

13. Tomberg J, Unemo M, Ohnishi M, Davies C, Nicholas RA. Identification of amino acids conferring high-level resistance to expanded-spectrum cephalosporins in the penA gene from Neisseria gonorrhoeae strain Ho41. Antimicrob Agents Chemother. 2013;57(7):3029-36. https://doi.org/10.1128/ AAC.00093-13 PMID: 23587946

14. Bignell C, Unemo MEuropean STI Guidelines Editorial Board. 2012 European guideline on the diagnosis and treatment of gonorrhoea in adults. Int J STD AIDS. 2013;24(2):85-92. https://doi.org/10.1177/0956462412472837 PMID: 24400344

15. Fifer H, Natarajan U, Jones L, Alexander S, Hughes G, Golparian $D$, et al. Failure of dual antimicrobial therapy in treatment of gonorrhea. N Engl J Med. 2016;374(25):2504-6. https://doi. org/10.1056/NEJMC1512757 PMID: 27332921

16. Cole MJ, Spiteri G, Jacobsson S, Woodford N, Tripodo F, AmatoGauci AJ, et al. Overall low extended-spectrum cephalosporin resistance but high azithromycin resistance in Neisseria gonorrhoeae in 24 European countries, 2015. BMC Infect Dis. 2017;17(1):617. https://doi.org/10.1186/s12879-017-2707-Z PMID: 28893203

17. Anbefalinger om forebyggelse, diagnose og behandling af sexuelt overførbare infektioner. [Recommendations on prevention, diagnosis and treatment of sexually transmitted infections]. Copenhagen: Sundhedsstyrelsen; 2015. Danish. Available from: https://www.sst.dk/da/udgivelser/2015/ /med ia/9881BBoE837B41DAAE0954A1A8D798B9.ashx

18. European Committee on Antimicrobial Susceptibility Testing (EUCAST). Antimicrobial wild type distributions of Neisseria gonorrhoeae MICs. Växjö: EUCAST. [Accessed 21 Sep 2017]. Available from: https://mic.eucast.org/Eucast2/ SearchController/search.jsp?action=performSearch\&BeginInde $x=0 \&$ Micdif $=$ mic \& Numberlnde $=50 \&$ Antib $=-1 \&$ Specium $=169$

19. Bartels MD, Larner-Svensson H, Meiniche $H$, Kristoffersen $K$, Schonning K, Nielsen JB, et al. Monitoring meticillin resistant Staphylococcus aureus and its spread in Copenhagen, Denmark, 2013, through routine whole genome sequencing. Euro Surveill. 2015;20(17):21112. https://doi.org/10.2807/15607917.ES2015.20.17.21112 PMID: 25955776

20. Unemo M, Golparian D, Sánchez-Busó L, Grad Y, Jacobsson S, Ohnishi M, et al. The novel 2016 WHO Neisseria gonorrhoeae reference strains for global quality assurance of laboratory investigations: phenotypic, genetic and reference genome characterization. I Antimicrob Chemother, 2016:71(11):3096 108. https://doi.org/10.1093/jac/dkw288 PMID: 27432602

21. Statens Serum Institut. Gonorré 2016. [Gonorrhoea 2016]. EPI-NYT. 2017;18. Danish. Available from: http://www.ssi.dk/ Aktuelt/Nyhedsbreve/EPI-NYT/2017/Uge 18 - 2017.aspx

22. Läkemedelsverket. Sexuellt överförbara bakteriella infektionerbehandlingsrekommendation. [Sexually transmitted bacterial infections - treatment recommendation]. Information från Läkemedelsverket. 2015;1:16-31. Swedish. Available from: https://lakemedelsverket.se/upload/halso-och-sjukvard/ behandlingsrekommendationer/Sexuellt overforbara bakteriella_infektioner_behandlingsrekommendation_webb. pdf

\section{License and copyright}

This is an open-access article distributed under the terms of the Creative Commons Attribution (CC BY 4.0) Licence. You may share and adapt the material, but must give appropriate credit to the source, provide a link to the licence, and indicate if changes were made.

This article is copyright of the authors, 2017. 